\title{
Investigation into breast cancer and partial breast reconstruction: A review
}

\author{
Mohammad Reza Ebadi (1), Maryam Kazemi Aghdam (2), Zeinab Safarpour Lima (3), \\ Ladan Younesi (3)
}

(1) Department of Plastic and Reconstructive Surgery, Hazrat-e Fateme Hospital, Burn Reseach Center, Iran University of Medical Sciences (IUMS), Tehran, Iran; (2) Pediatric Pathology Research Center, Institute for Children Health, Shahid Beheshti University of Medical Sciences, Tehran, Iran; (3) Shahid Akbarabadi Clinical Research Development Unit (ShACRDU), Iran University of Medical Sciences (IUMS), Tehran, Iran

This article is distributed under the terms of the Creative Commons Attribution Noncommercial License (CC BY-NC 4.0) which permits any noncommercial use, distribution, and reproduction in any medium, provided the original author(s) and source are credited.

\begin{abstract}
Growing increasingly in South America, Africa and Asia, breast cancer is known as the dominant type of cancer in women. Different treatments are available for breast cancer, among which surgery is the most widely used, but researchers are trying to develop new strategies. One of the most prominent surgical methods is referred to as oncoplastic surgery, that helps to remove segments of malignant breast tissue. This type of surgery aims to obtain vast surgical margins, while the remaining tissue is rearranged so that the better cosmetic outcome is obtained. This review will investigate the breast cancer and then discuss partial breast reconstruction. Before outlining the procedures, the different types of partial breast reconstruction will be discussed. Finally, advantages and disadvantages will be outlined. MEDLINE database was used to conduct the search. The main terms used were 'Conservation Breast Surgery Reconstruction' AND 'Oncoplastic Surgery', 'Partial Mastectomy Reconstruction' AND 'Conservative Breast Surgery Reconstruction', 'oncoplastic' [All Fields], 'breast' AND 'surgery' OR 'surgery' operative', 'oncoplastic' ('breast')'. The bibliographies of relevant papers were manually searched up to October 2018, but more recent voices are also included.
\end{abstract}

Key Words: Breast Cancer, Oncoplastic Surgery, Partial Breast Reconstruction.

Eur J Transl Myol 29 (2): 79-85, 2019

Breast cancer is known as the dominant type of cancer in women, about 232,000 cases are reported annually in the United States. ${ }^{1,2}$ Breast cancer constitutes $22.9 \%$ of all invasive cancers in women. Invasive breast cancer refers to a cancer which affects ducts, glands and other parts of the breast. ${ }^{3}$

\section{Prevalence and Risk Factors}

The incidence of breast cancers grows with increasing age. The Centers for Disease Control and Prevention reported that the age group 70-74 years is most vulnerable. According to the UK Cancer Research, approximately 54,900 cases of breast cancer are reported annually in the UK. Furthermore, it is the most common type of cancer in the UK, accounting for $15 \%$ of all new cases. ${ }^{4}$ Breast cancer is the most common invasive cancer in women worldwide, affecting $12 \%$ of women.

Several risk factors for breast cancer are presented in Table 1.5

\section{Benign breast disease}

Non-invasive non-melanoma breast skin tumor is the most common begnin diesease, that it is easy to treat. Indeed it accounts to few deaths. Genetics, higher levels of hormones, obesity, dietary patterns and lack of breastfeeding are some of the main risk factors. Exposure to light pollution can increase the likelihood of breast cancer. Changes in hormone balances during normal, monthly menstrual cycles can lead to symptomatic breast changes for some women. Cysts are defined as tiny, benign, fluid-filled sacs that are problematic for women. Lump size may intensify the week before the menstrual period and lessen a week after. Some benign breast conditions include gynaecomastia, benign phyllodes tumor, breast pain, breast cysts, breast calcifications, Lobular neoplasia, sclerosing lesions of the breast, Mondor's disease, duct ectasia, intraductal papilloma, fibroadenoma, hyperplasia, intertrigo (rash under the 


\section{Breast cancer and partial breast reconstruction}

Eur J Transl Myol 29 (2): 79-85, 2019

\begin{tabular}{|c|c|}
\hline \multicolumn{2}{|r|}{ Table 1. Risk factors of brest cancer } \\
\hline Risk factor & Explanation \\
\hline Age & Older women are more likely to develop breast cancer. \\
\hline Family History & Women with a history of breast cancer are more likely to develop breast cancer. \\
\hline Genetics & Approximately $5 \%$ to $10 \%$ of breast cancers are attributed to hereditary factors. \\
\hline History of Breast Cancer & $\begin{array}{l}\text { Patients with breast cancer are more likely to develop a new cancer in the other breast or a } \\
\text { different part of the same breast. }\end{array}$ \\
\hline Certain Breast Changes & Several types of benign breast conditions may affect breast cancer risk. \\
\hline Race/Ethnicity & $\begin{array}{l}\text { White women are more likely to develop breast cancer than African American, Hispanic, and } \\
\text { Asian women. }\end{array}$ \\
\hline Smoking & $\begin{array}{l}\text { Smoking is reported to increase the risk of developing breast cancer in younger, premenopausal } \\
\text { women. }\end{array}$ \\
\hline Diet & According to the reports, diet accounts for approximately $30 \%$ to $40 \%$ of all cancers. \\
\hline Dense Breasts & $\begin{array}{l}\text { According to the reports, dense breasts are } 6 \text { times more likely to develop cancer. This can } \\
\text { complicate the detection of breast cancer. }\end{array}$ \\
\hline
\end{tabular}

breast), periductal mastitis, fat necrosis and atypical hyperplasia. ${ }^{6}$

\section{Clinical Presentation of Breast Cancer}

Some of the main symptoms include pain in breast or pain in the nipple area, new lump in the breast, thickening or swelling of part of the breast, nipple discharge other than breast milk, new lump in the breast or underarm, redness or flaky skin in the nipple, dimpling of breast skin and change in the size or the shape of the breast. ${ }^{7,8}$

\section{Types of Breast Cancer}

Breast cancer may develop in the lobules, the milk ducts or the tissue in between. ${ }^{9}$ Different types of breast cancer are presented in Table 2.

\section{Diagnosis}

Several types of breast cancer can be diagnosed with biopsy of the affected area in the breast. However, some types of breast cancer need specialized laboratory examinations. Mammography and physical examination of the breasts can determine whether a lump is a cancer. These two methods may also be used to detect some other lesions. Some of the most common methods of diagnosis include Axillary lymph node dissection, Lymph node biopsy, including Sentinel lymph node biopsy, Health history and physical exam, Fine needle aspiration, Diagnostic mammography, human epidermal growth

Table 2. Types of brest cancer
- Inflammatory Breast Cancer
- Medullary Carcinoma of the Breast
- Ductal Carcinoma In Situ
- Lobular Carcinoma In Situ
- Invasive Ductal Carcinoma
- Papillary Carcinoma of the Breast
- Mucinous Carcinoma of the Breast
- Invasive Lobular Carcinoma

factor receptor 2 status testing, Hormone receptor status testing (such as estrogen receptors, Scintimammography and progesterone receptors. ${ }^{10,11}$

\section{Treatment of Breast Cancer}

Breast cancer can be treated with several methods. Surgery is the most widely used method that removes physically the tumor. ${ }^{12,13}$ Some types of treatments for breast cancer are outlined as follows.

Therapies with drugs

In this type of therapy, chemical drugs are used to kill the cancer cells. Some of the systemic therapies used in this area include hormonal therapy, chemotherapy and targeted therapy. ${ }^{14-17}$ The most commonly used drugs for chemotherapy are summarized in Table 3.

\section{Radiation Therapy}

Radiotherapy can be used to kill tumor cells. It may positively affect the tumor microenvironment. Brachytherapy (internal radiotherapy) and external beam

Table 3. Chemotherapy drugs for breast cancer

- Vinorelbine (Navelbine)

- Protein-bound paclitaxel (Abraxane)

- Paclitaxel (Taxol)

- Methotrexate (Rheumatrex, Trexall)

- Ixabepilone (Ixempra)

- Gemcitabine (Gemzar)

- Fluorouracil (5-FU, Efudex)

- Doxorubicin

- Docetaxel (Taxotere)

- Cyclophosphamide

- Eribulin (Halaven)

- Epirubicin (Ellence)

- Pegylated liposomal doxorubicin (Doxil)

- Cisplatin

- Carboplatin

- Capecitabine (Xeloda) 


\section{Breast cancer and partial breast reconstruction}

Eur J Transl Myol 29 (2): 79-85, 2019

Table 4. Radiation therapy for breast cancer

- External-beam radiation therapy: Known as the most common type of radiation treatment, external beam radiotherapy is delivered outside the body using a machine.

- Brachytherapy: This therapy beams radioactive sources into the tumor.

- Intra-operative radiation therapy: A probe is used to perform this type of therapy.

radiotherapy are two types of radiotherapy. Radiation can also be delivered during the operation on the breast cancer. The common types of radiation therapy are presented in Table 4.

\section{Surgery}

Some of the treatments include targeted therapy, chemotherapy, radiation therapy, surgery and hormonal therapy. Surgeries may range from mastectomy to breastconserving surgery. Breast reconstruction can be applied during the surgery or later. Cancers with greater risk of recurrence may be treated with surgery. Mastectomy is used to remove the entire breast, while lumpectomy aims to remove the suspicious or cancerous spot. The physical removal of the tumor occurs during surgery. It is possible to perform biopsy on one or more lymph nodes during the surgery. ${ }^{18}$ Some women prefer to undergo contralateral prophylactic mastectomy. Non-surgical methods such as radiation therapy are used to target and destroy the cancerous cells. ${ }^{19,20}$ ). Breast reconstruction may be performed during surgery or later. Once cancer spreads to other parts of the body, treatments attempt to improve the quality of life of the patients. Nipple prosthesis can be applied, once the mastectomy is over. ${ }^{21}$ There are two main purposes behind breast cancer surgery. This type of surgery aims to treat the breast cancer successfully and reconstruct the psychosocial perspectives, including image and sexual well-being or self-perception. ${ }^{22}$ It is important for women to be able to wear a bra and feel physically balanced in breast shape and size. ${ }^{23}$ The two purposes mentioned above should be taken into consideration in order to make appropriate decisions for breast cancer treatment. Surgeries may range from mastectomy to breast-conserving surgery. Combined with breast conservation therapy (BCT), oncoplastic approach can be used to treat breast cancer. Women with breast cancer are reportedly more comfortable with this safe method. Using this therapy, they can save breast tissue and shape. ${ }^{24}$ Accordingly, $\mathrm{BCT}$, by combining the oncology principles with plastic surgery, contributes to the appropriate management of cancer. Furthermore, it improves tumor extirpation and minimizes the potential for a BCT deformity. Partial breast reconstruction was first introduced in the UK in 1990s. The patients are mostly concerned about the choice between breast conservation and mastectomy. For this purpose, plastic surgeons and surgical oncologist can help patients make the right decision. ${ }^{25,26}$

Partial Breast Defects Classification and Oncoplastic Techniques for Type of Breast Defects

Breast deformities can be classified by several methods. Some of the most important classifications include breast reshaping, primary closure and local and distant flaps The oncoplastic techniques which can be used for different types of breast defects are presented in Table 5. It should be pointed out that some of the classifications are associated with delayed reconstruction. ${ }^{27}$ Considering the response to reconstruction, Clough et al. could classify the oncoplastic procedures and breast defects. Patients who suffer from Type-I breast deformity have normally shaped breast, without any other deformities. However, patients with Type-II deformity usually suffer from deformed breasts. They are typically treated with reconstruction or mastectomy. ${ }^{28}$ Partial mastectomyrelated breast deformity can mostly be reduced. Partial breast reconstruction can be used after the partial mastectomy. There is no need for reconstruction in small

Table 5. Different types of breast defects and suggested oncoplastic techniques

\begin{tabular}{|c|c|}
\hline Type of breast defects & Oncoplastic technique required \\
\hline Types IA, IIA and IIIA & Breast tissue advancement flaps \\
\hline Type IB & Latissimus Dorsi Myocutaneous flap \\
\hline Type IC & skin-sparing mastectomy \\
\hline Type IIC & $\begin{array}{c}\text { Lateral Thoracodorsal Flap or } \\
\text { Latissimus Dorsi Myocutaneous Flap }\end{array}$ \\
\hline Type IIIB & Bilateral Reduction Mammaplasty \\
\hline Type IIIC & Bilateral Reduction Mammaplasty \\
\hline
\end{tabular}




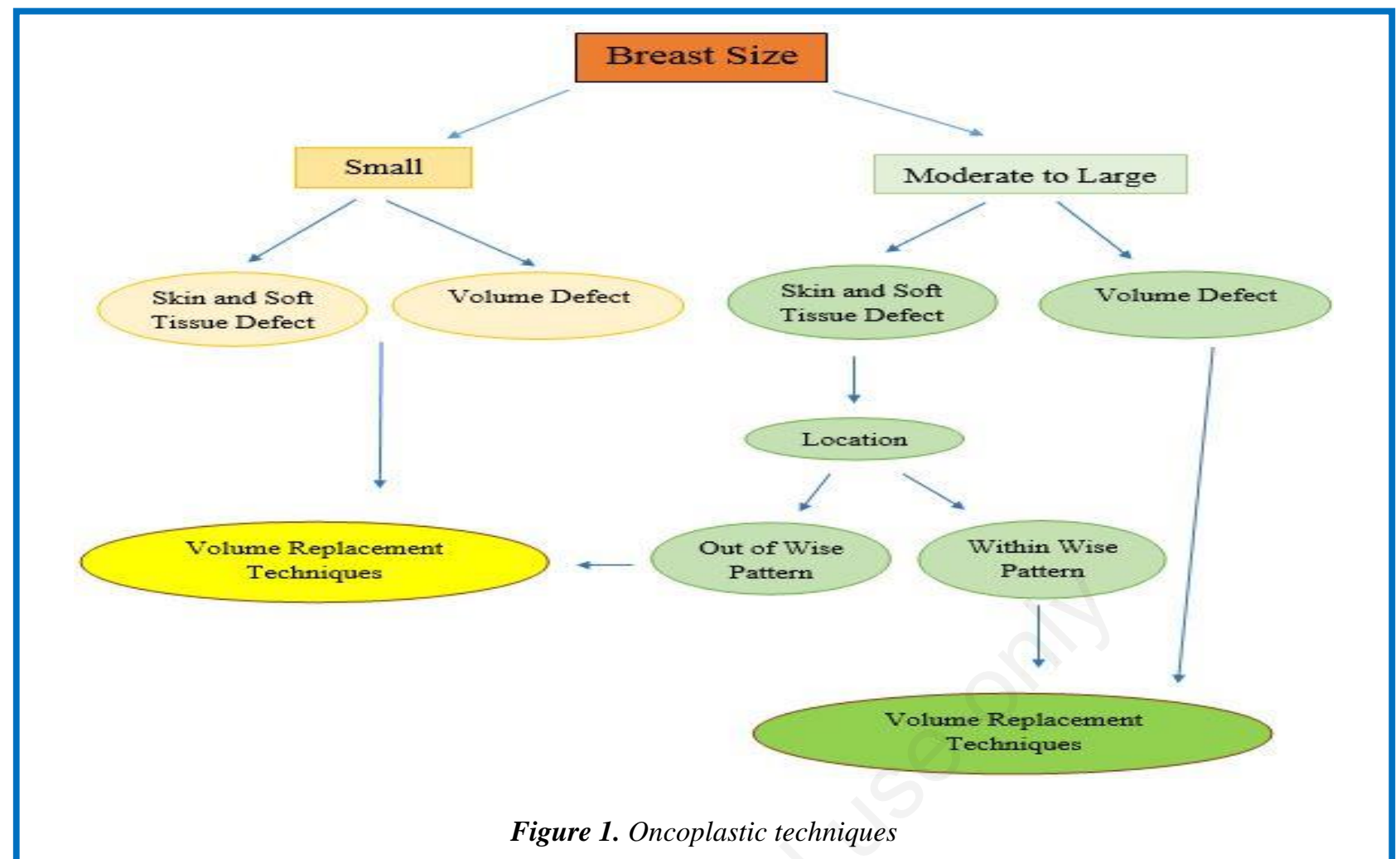

defects in large breasts. For larger defects, breast reshaping and a contralateral breast reduction can be taken into consideration. For this purpose, it is necessary to choose appropriate techniques or a combination of procedures. It should be mentioned that reconstruction techniques are often performed with bilateral reduction mammaplasty, latissimus dorsi myocutaneous flap, breast tissue advancement flaps, abdominal flaps, bilateral mastopexy, and lateral thoracodorsal flap. Regarding the use of distant flaps in CBS, more appropriate techniques have been unanimously chosen. ${ }^{29}$ Size and location of tumor in breast are two of the influencing factors that should be taken into consideration. In some patients, chemotherapy may be used to shrink the tumor. Once that process is over, the patients may undergo surgery. ${ }^{30,31}$ Plastic surgeon may evaluate the degree of ptosis, any evidence of prior radiation, overall skin quality and breast size. The size of the breast and affected region should be paid great attention (Figure 1). Patient with smaller size of breast suffer from low volume of glandular tissue. For this purpose, they may be in need of regionally-based flaps. It is essential to apply oncoplastic principles to reconstruction and mastectomy. It is also important to understand different varieties of mastectomy techniques in order to obtain the optimal outcomes. Given the tumor location, the appropriate reduction technique and the design of the nipple/areolar pedicle are selected. ${ }^{32,33}$ While maintaining the breast shape and appearance, the cancer may be resected with surgical margins. For a surgery to be performed successfully, it is necessary to use breast imaging because it is capable of predicting the orientation of disease and histological extent accurately. Mammography detects asymptomatic breast cancers Imaging methods can be efficiently used to diagnose the tumor mass. ${ }^{34}$ Volume replacement and volume displacement are among the most widely used types of reconstruction, each of which have different techniques. Some of the techniques specifically attributed to the volume replacement are primary closure mirror (such as biopsy/excisions; batwing mastopexy), reduction mastopexy, breast flap and parenchymal (such as remodeling, volume shrinkage). ${ }^{35}$ While the techniques specifically attributed to the volume replacement are distant flaps, adjacent or distant tissue transfer, local flaps (such as fascio cutaneous, perforator), implant augmentation and volume preserving. Depending on the size of tumor, location of tumor, breast size and patient's desires, volume displacement may seem much more appropriate. ${ }^{36}$ Oncoplastic surgery is a combination of the principles of plastic surgery and oncology. It uses breast flap advancement to address tissue defects and improve cosmesis. Breast conserving surgery (BCS) followed by radiation treatment comprises BCT. Masetti et al. developed a four-step design for oncoplastic operations which can be applied in several cases. ${ }^{21,37,38}$ Fundamentally, oncoplastic procedures attempt to minimize cosmetic detriment to the breast.

\section{Clinical Outcomes of Breast Reconstruction}

Breast cancer reconstruction still remains a challenging area for oncologists and plastic surgeons. Before performing radiotherapy, an optimal treatment is needed. ${ }^{25,39}$ So far, there is not sufficient evidence for the 
aesthetic clinical and safety results of the oncoplastic techniques. This can be attributed to the small number of patients and less experienced surgeons. In the past, cancer was described as a systemic illness, Then, several sparing procedures were developed. However, it is necessary to collect sufficient data on the metastasis and overall survival in these procedures. ${ }^{40}$ Kronowitz et al. examined 69 patients and reported recurrent oncoplastic reconstructions $(\mathrm{P}=0.06){ }^{25}$ In addition, Clough et al. ${ }^{28}$ investigated the patients who had undergone oncoplastic reconstruction and BCS. Local recurrence was reported in 11 cases (5-year local recurrence rate was 9.4\%). Accordingly, 8 patients died and 13 patients developed metastases. ${ }^{41}$ Oncoplastic procedures suffer from limited evidence regarding the aesthetic results. There are several methods for aesthetic evaluation. ${ }^{42}$ According to some authors, glandular and skin tissue resection can affect the aesthetic outcome. ${ }^{43}$

Advantages and Disadvantages of Partial Breast Reconstruction

Mastectomy and implant reconstruction offers several advantages for good candidates of oncoplastic reconstruction. ${ }^{26,44,45}$ Oncological safety is one of the most prominent advantages of partial breast reconstruction. ${ }^{40}$ Anderson et al. investigated different oncoplastic approaches for partial mastectomy. Partial breast reconstruction is capable of enhancing the probability of achieving better surgical margins. Surgical treatments of breast cancer have their own advantages and disadvantages. Oncoplastic breast surgery can be used to obtain optimal aesthetic outcomes for women with breast cancers, especially for women who would not obtain acceptable outcomes with other techniques. It is essential to apply oncoplastic principles to mastectomy and reconstruction and to understand the different varieties of mastectomy techniques to obtain the better outcomes, but further research is required to examine the capacities of some other methods, such as flap operations.

\section{Limitations of Oncoplastic Breast Surgery}

Oncoplastic breast surgery may delay the adjuvant therapy and lead to some complications. Complications of oncoplastic reconstruction are nipple areola complex necrosis, skin/flap necrosis, seroma, hematoma, infection, fat necrosis and wound dehiscence. Recently, it was reported that the average complication rate for the oncoplastic reduction mammaplasty group and the oncoplastic flap reconstruction group was $16 \%$ and $14 \%$, respectively. Accordingly, the initiation of adjuvant therapy was not delayed. Complications in oncoplastic groups may not negatively affect patient care. To reduce morbidity rate, it is essential to select proper techniques.

\section{Conclusion}

Oncoplastic approaches are used to obtain better outcomes for women with breast cancer, attempting to minimize cosmetic detriment to the breast.

\section{List of acronyms}

BCS - breast conserving surgery

$\mathrm{BCT}$ - breast-conservaing therapy

\section{Authors contributions}

All authors played a role in the conception and study design, data acquisition and analysis, drafting, and approval of the final version.

\section{Acknowledgments None.}

Funding No funding was obtained for this research project.

\section{Conflict of Interest}

The authors declare they have no financial, personal, or other conflicts of interest.

\section{Ethical Publication Statement}

We confirm that we have read the Journal's position on issues involved in ethical publication and affirm that this report is consistent with those guidelines.

\section{Corresponding Author}

Ladan Younesi, Shahid Akbar Abadi Clinical Research Development Unit (ShCRDU), Iran University of Medical Sciences (IUMS), Tehran, Iran.

Tel: 00989124966317

Email: younesi.1@iums.ac.ir

E-mails of co-authors

Mohammad Reza Ebadi: mre5md@yahoo.com Maryam Kazemi Aghdam:

m_kazemi_aghdam@yahoo.com

Zeinab Safarpour Lima: safarpourlima.z@iums.ac.ir

\section{References}

1. Tao Z, Shi A, Lu C, et al. Breast cancer: epidemiology and etiology. Cell Biochem Biophys 2015;72:333-8. doi: 10.1007/s12013-014-0459-6.

2. DeSantis CE, Fedewa SA, Goding Sauer A, et al. Breast cancer statistics, 2015: Convergence of incidence rates between black and white women. CA Cancer J Clin 2016;66:31-42. doi: 10.3322/ caac.21320. Epub 2015 Oct 29.

3. Gradishar WJ, Anderson BO, Balassanian R, et al. Invasive breast cancer version 1.2016, NCCN clinical practice guidelines in oncology. J Natl Compr Canc Netw 2016;14:324-54.

4. Vahabi M, Lofters A, Kumar M, Glazier RH. Breast cancer screening disparities among urban immigrants: a population-based study in Ontario, Canada. BMC Public Health 2015;15:679. doi: 10.1186/s12889-015-2050-5.

5. Yang XR, Chang-Claude J, Goode EL, et al. Associations of breast cancer risk factors with tumor subtypes: a pooled analysis from the Breast Cancer Association Consortium studies. J Natl Cancer Inst 2011;103:250-63. doi: 10.1093/jnci/ djq526. Epub 2010 Dec 29. 


\section{Breast cancer and partial breast reconstruction}

Eur J Transl Myol 29 (2): 79-85, 2019

6. Diego EJB. Benign Breast Tumors. Breast Disease: Springer; 2016. p. 23-56.

7. Crew KD, Greenlee H, Capodice J, et al. Prevalence of joint symptoms in postmenopausal women taking aromatase inhibitors for early-stage breast cancer. J Clin Oncol 2007;25:3877-83.

8. Norman SA, Localio AR, Potashnik SL, et al. Lymphedema in breast cancer survivors: incidence, degree, time course, treatment, and symptoms. J Clin Oncol 2009;27:390-7. doi: 10.1200/JCO.2008. 17.9291. Epub 2008 Dec 8..

9. Weigelt B, Horlings H, Kreike B, et al. Refinement of breast cancer classification by molecular characterization of histological special types. J Pathol 2008;216:141-50. doi: 10.1002/path.2407.

10. Stanton AL, Danoff-burg S, Huggins ME. The first year after breast cancer diagnosis: hope and coping strategies as predictors of adjustment. Psychooncology 2002;11:93-102.

11. Wolberg WH, Street WN, Mangasarian OL. Computer-derived nuclear features compared with axillary lymph node status for breast carcinoma prognosis. Cancer. 1997;81:172-9.

12. Miller KD, Siegel RL, Lin CC, et al. Cancer treatment and survivorship statistics, 2016. CA Cancer J Clin 2016;66:271-89. doi: 10.3322/caac. 21349. Epub 2016 Jun 2.

13. De Groef A, Van Kampen M, Dieltjens E, et al. Effectiveness of postoperative physical therapy for upper-limb impairments after breast cancer treatment: a systematic review. Archiv Physical Med Rehabil 2015;96:1140-53. doi: 10.1016/j. apmr.2015.01.006. Epub 2015 Jan 13.

14. Early Breast Cancer Trialists' Collaborative Group (EBCTC). Effects of chemotherapy and hormonal therapy for early breast cancer on recurrence and 15-year survival: an overview of the randomised trials. Lancet 2005;365 (9472):1687-717.

15. Quist J, Mirza H, Cheang MCU, et al. A Four-gene Decision Tree Signature Classification of Triplenegative Breast Cancer: Implications for Targeted Therapeutics. Mol Cancer Ther 2019;18:204-212. doi: 10.1158/1535-7163.MCT-18-0243. Epub 2018 Oct 10.

16. Taylor CW, Wang Z, Macaulay E, et al. Exposure of the heart in breast cancer radiation therapy: a systematic review of heart doses published during 2003 to 2013. Int J Radiat Oncol, Biol, Phys 2015;93:845-53. doi: 10.1016/j.ijrobp.2015.07. 2292. Epub 2015 Aug 3.

17. Smith BL, Gadd MA, Lanahan CR, et al. Real-time, intraoperative detection of residual breast cancer in lumpectomy cavity walls using a novel cathepsinactivated fluorescent imaging system. Breast Cancer Res Treat 2018;171:413-420. doi: 10.1007/s10549-018-4845-4. Epub 2018 Jun 9.

18. Lyman GH, Somerfield MR, Bosserman LD, et al. Sentinel lymph node biopsy for patients with early- stage breast cancer: American Society of Clinical Oncology clinical practice guideline update. J Clin Oncol 2017;35:561-564 doi: 10.1200/JCO.2016. 71.0947. Epub 2016 Dec 12.

19. Benson J, Winters Z. Contralateral prophylactic mastectomy. Br J Surg 2016;103:1249-50. doi: 10.1002/bjs.10223. Epub 2016 Jul 28.

20. Wong SM, Freedman RA, Sagara Y, et al Growing use of contralateral prophylactic mastectomy despite no improvement in long-term survival for invasive breast cancer. Ann Surg 2017;265:581-9.

21. Smith ML, Molina BJ, Dayan E, et al. Defining the Role of Free Flaps in Partial Breast Reconstruction. Journal of reconstructive microsurgery 2018;34:185-92.

22. Bashandy GMN, Abbas DN. Pectoral nerves I and II blocks in multimodal analgesia for breast cancer surgery: a randomized clinical trial. Reg Anesth Pain Med 2015;40:68-74.

23. McGuire A, Lowery AJ, Kell MR, et al. Locoregional recurrence following breast cancer surgery in the trastuzumab era: A systematic review by subtype. Ann Surg Oncol 2017;24:3124-32.

24. Losken A, Hamdi M. Partial breast reconstruction: current perspectives. Plast Reconstr Surg 2009;124:722-36.

25. Kronowitz SJ, Feledy JA, Hunt KK, et al. Determining the optimal approach to breast reconstruction after partial mastectomy. Plast Reconstr Surg 2006;117:1-11.

26. Bajaj AK, Kon PS, Oberg KC, Miles DA. Aesthetic outcomes in patients undergoing breast conservation therapy for the treatment of localized breast cancer. Plast Reconstr Surg 2004;114:14429.

27. Losken A, Styblo TM, Carlson GW, et al. Management algorithm and outcome evaluation of partial mastectomy defects treated using reduction or mastopexy techniques. Ann Plast Surg 2007;59:235-42.

28. Clough KB, Kroll SS, Audretsch W. An approach to the repair of partial mastectomy defects. Plast Reconstr Surg 1999;104:409-20.

29. Munhoz AM, Montag E, Gemperli R. Oncoplastic breast surgery: indications, techniques and perspectives. Gland Surg 2013;2:143.

30. Fisher B, Bryant J, Wolmark N, et al. Effect of preoperative chemotherapy on the outcome of women with operable breast cancer. J Clin Oncol 1998;16:2672-85.

31. Wolmark N, Wang J, Mamounas E, et al. Preoperative chemotherapy in patients with operable breast cancer: nine-year results from National Surgical Adjuvant Breast and Bowel Project B-18. J Natl Cancer Inst Monogr 2001;30:96-102.

32. van der Hage JA, van de Velde CJ, Julien JP, et al. Preoperative chemotherapy in primary operable 


\section{Breast cancer and partial breast reconstruction}

Eur J Transl Myol 29 (2): 79-85, 2019

breast cancer: results from the European Organization for Research and Treatment of Cancer trial 10902. J Clin Oncol 2001;19:4224-37.

33. Mieog SJ, Van der Hage JH, van de Velde CC. Preoperative chemotherapy for women with operable breast cancer. Cochrane Database Syst Rev 2007;(2):CD005002.

34. Friedewald SM, Rafferty EA, Rose SL, et al. Breast cancer screening using tomosynthesis in combination with digital mammography. Jama 2014;311:2499-507. doi: 10.1001/jama.2014.6095.

35. Barrio AV, Eaton A, Frazier TG. A prospective validation study of bioimpedance with volume displacement in early-stage breast cancer patients at risk for lymphedema. Ann Surg Oncol 2015;22 Suppl 3:S370-5. doi: 10.1245/s10434-015-4683-0. Epub 2015 Jun 18.

36. Noguchi M, Yokoi-Noguchi M, Ohno Y, et al. Oncoplastic breast conserving surgery: volume replacement vs. volume displacement. Eur J Surg Oncol 2016;42:926-34. doi: 10.1016/j.ejso.2016. 02.248. Epub 2016 Mar 4. Review.

37. McCulley SJ, Schaverien MV, Tan VK, Macmillan RD. Lateral thoracic artery perforator (LTAP) flap in partial breast reconstruction. J Plast Reconstr Aesthet Surg 2015;68:686-91. doi: 10.1016/j.bjps.2015.01. 008. Epub 2015 Jan 27.

38. Kashiwagi K, Abe Y, Ishida S, et al. Reduction mammaplasty and mastopexy for the contralateral breast after reconstruction surgery following cancer resection: A report of 3 cases. J Med Invest 2016;63:281-5. doi: 10.2152/jmi.63.281.

39. Munhoz AM, Aldrighi CM, Montag E, et al. Outcome analysis of immediate and delayed conservative breast surgery reconstruction with mastopexy and reduction mammaplasty techniques. Ann Plast Surg 2011;67:220-5.

40. Kaur N, Petit J-Y, Rietjens M, et al. Comparative study of surgical margins in oncoplastic surgery and quadrantectomy in breast cancer. Ann Surg Oncol 2005;12:539-45.

41. Clough KB, Lewis JS, Couturaud B, et al. Oncoplastic techniques allow extensive resections for breast-conserving therapy of breast carcinomas. Ann Surg 2003;237:26-34.

42. Asgeirsson K, Rasheed T, McCulley S, Macmillan R. Oncological and cosmetic outcomes of oncoplastic breast conserving surgery. Eur J Surg Oncol 2005;31:817-23.

43. Mills JM, Schultz DJ, Solin LJ. Preservation of cosmesis with low complication risk after conservative surgery and radiotherapy for ductal carcinoma in situ of the breast. Int J Radiat Oncol Biol Phys 1997;39:637-41.

44. Anderson BO, Masetti R, Silverstein MJ. Oncoplastic approaches to partial mastectomy: an overview of volume-displacement techniques. Lancet Oncol 2005;6:145-57.

45. Munhoz AM, Montag E, Arruda EG, et al. Critical analysis of reduction mammaplasty techniques in combination with conservative breast surgery for early breast cancer treatment. Plast Reconstr Surg 2006;117:1091-103.

Submissions: March, 9, 2019

Revision received: April 11, 2019

Acceptance: April 11, 2019 